\title{
FÓRUM
}

Submetido 14.07.2020. Aprovado 18.11.2020

Avaliado pelo sistema double blind review. Editores convidados: Alessandra de Sá Mello da Costa, Ely Laureano Paiva, Marcus Vinícius Peinado Gomes e Vinicius Brei

Versão original

DOI: http://dx.doi.org/10.1590/So034-759020200605

\section{ATUAÇÃO EMPRESARIAL PARA SUSTENTABILIDADE E RESILIÊNCIA NO CONTEXTO DA COVID-19}

\author{
Business action on sustainability and resilience in the context of COVID-19 \\ Acción empresarial para sostenibilidad y resiliencia en el contexto de la COVID-19
}

\begin{abstract}
RESUMO
O enfrentamento da crise da Covid-19 ressaltou a importância do olhar crítico e sistêmico para a atuação empresarial para sustentabilidade. Este artigo tem como objetivo discutir a sustentabilidade, através das lentes teóricas de sustentabilidade "forte" e "fraca" e suas relações com os paradigmas econômicos; apresentar a teoria da resiliência como alternativa frente aos atuais desafios; e analisar, com base nos conceitos apresentados, indícios de como as organizações estão reagindo inicialmente, em suas atuações com sustentabilidade, à crise da Covid-19. Para tanto, foram realizadas entrevistas semiestruturadas com empresas que atuam no Brasil. Como resultado, indícios de realinhamento ao propósito inicial da empresa de criar valor para a sociedade coexistem com indícios de continuidade da aposta em soluções via mercado e da busca por crescimento infinito em um planeta com recursos limitados.
\end{abstract}

MARIANA NICOLLETTI ${ }^{1}$ mariana.nicolletti@fgv.br 0000-0003-1339-8110

\section{GABRIELA ALEM ${ }^{1}$}

gabriela.alem@fgv.br 0000-0001-7584-277X

\section{MARTA BLAZEK ${ }^{1}$}

marta.blazek@fgv.br 0000-0002-5270-7521

PAOLA FILLIPPI 1 paola.fillippi@fgv.br 0000-0002-7487-112X

LUIS FELIPE BISMARCHI² fbismarchi@gmail.com 0000-0003-1569-6998

${ }^{1}$ Fundação Getulio Vargas, Centro de Estudos em Sustentabilidade da Escola de Administração de Empresas de São Paulo, São Paulo, Brasil

2 Universidade de São Paulo, Programa de Pós-Graduação em Ciência Ambiental, São Paulo, Brasil
PALAVRAS-CHAVE | Resiliência, sustentabilidade, economia ecológica, Covid-19, gestão empresarial.

\section{ABSTRACT}

Facing up to the COVID-19 crisis has emphasized the importance of taking a critical and systemic look at business action for sustainability. The aims of this article are: to discuss sustainability, through the theoretical lenses of 'strong' and 'weak' sustainability and its relationship with economic paradigms; to present the theory of resilience as an alternative to the current challenges; and, based on the concepts presented, to analyze the indications of how organizations are reacting to the crisis. To this end, semi-structured interviews were conducted with companies operating in Brazil. As a result it was found that signs of the realignment of the companies' initial purpose of creating value for society coexist alongside signs of continued investment in market-based solutions and the search for infinite growth on a planet with limited resources.

KEYWORDS / Resilience, sustainability, ecological economics, COVID-19, business management.

\section{RESUMEN}

El enfrentamiento de la crisis de COVID-19 enfatizó la importancia de una visión crítica y sistémica sobre la acción empresarial para la sostenibilidad. Este artículo tiene como objetivo discutir la sostenibilidad, a través de las lentes teóricas de la sostenibilidad 'fuerte' y 'débil' y sus relaciones con los paradigmas económicos, presentando la teoría de la resiliencia como una alternativa a los desafíos actuales y analizar, a partir de los conceptos presentados, los indicios de cómo las organizaciones están reaccionando a la crisis. Para ello, se realizaron entrevistas semiestructuradas con empresas que operan en Brasil. Como resultado, los signos de realineación con el propósito inicial de la empresa de crear valor para la sociedad coexisten con signos de inversión continua en soluciones basadas en el mercado y de búsqueda de un crecimiento infinito en un planeta con recursos limitados.

PALABRAS CLAVE / Resiliencia, sostenibilidad, economía ecológica, COVID-19, gestión empresarial. 


\section{INTRODUÇÃO}

A história da sustentabilidade empresarial revela que os comportamentos das organizações se adequam às pressões do contexto e o que funcionou em uma situação passa a não mais servir (Belinky, 2017). A humanidade vive hoje um contexto de extremas incerteza e instabilidade, em que forças de manutenção, de adaptação e transformação operam simultaneamente e pressionam empresas a lidar com elas, percebendo-as ou não, seja de maneira integrada e simultânea ou fragmentada e pontual. Uma das poucas certezas na crise atual é de que a reconstrução para melhor (building back better) descarta o retorno ao estado de onde se partiu e, portanto o favorecimento da força de manutenção; não apenas porque é impossível reconstituí-lo, mas também por estarem lá as causas do colapso (Monzoni \& Carvalho, 2020).

Se a pandemia da Covid-19 foi capaz de suspender o modus operandi automatizado, a ilusão sobre a imutabilidade das instituições e dos acordos sociais, e até mesmo o preceito neoliberal da austeridade fiscal (Santos, 2020; Harvey, 2020), pode ser também propulsora de uma reflexão crítica profunda sobre as premissas, crenças e os valores que regem os negócios. Essa reflexão é central para que alternativas ao modo de produção e consumo erigidos pelo capitalismo financeiro-rentista (BresserPereira, 2018) possam voltar à arena política, antes que novas crises sanitárias e calamidades insurjam da crise estrutural causada pela inversão da relação entre natureza, sociedade e economia (Liu, Rohr \& Li, 2013).

Os efeitos dessa inversão tornaram-se agudos com a Grande Aceleração, a partir de 1950, isto é, com a explosão populacional e o crescimento econômico ancorados na exploração intensiva do ambiente natural (Zalasiewicz, 2015). A pandemia reiterou que não há equilíbrio e igualdade entre as dimensões ambiental, social e econômica, como a sustentabilidade empresarial narrou por anos em suas representações. E mais: demonstrou as claras restrições impostas pela dimensão ambiental, que sustenta a vida e a produção econômica, e social, e se revela a desumanização do sistema econômico. A 'turbulência geopolítica', vislumbrada por 750 especialistas e tomadores de decisão que participaram do Fórum Econômico Mundial, em Davos, junta-se aos riscos ambientais e à sempre anunciada desaceleração econômica, na configuração de um mundo essencialmente instável e regido por incertezas (World Economic Forum, 2020).

Isso posto, este artigo dedica-se a discutir a sustentabilidade empresarial, a partir dos conceitos de sustentabilidade "forte" e "fraca" e à luz dos paradigmas econômicos; apresentar a teoria da resiliência como referência para a gestão empresarial diante da incerteza e instabilidade; e analisar, a partir dessas lentes e de uma pesquisa qualitativa com 13 empresas, indícios de como se acomodaram, adaptaram ou transformaram suas agendas de sustentabilidade no início da crise da Covid-19.

\section{REFERENCIAL TEÓRICO}

\section{Da sustentabilidade "fraca" à sustentabilidade "forte"}

A discussão teórica e as aplicações do conceito de sustentabilidade apresentam variedade, multidimensionalidade $\mathrm{e}$ ambiguidade na literatura (Redman, 2014). Por isso, o termo pode ser considerado em contínuo processo de formulação. Segundo Lélé (1991), a definição mais difundida sobre sustentabilidade refere-se à sua conotação ecológica, cujo significado trata das condições e padrões biofísicos necessários para suporte à vida humana, assumindo um nível especificado de bem-estar através das gerações futuras. Considera-se, portanto, nesta definição, não apenas o uso de recursos naturais para chegar ao bemestar, como também limitações determinadas pela natureza; em adição, o mesmo autor inclui as condições sociais na relação entre pessoas e natureza como determinantes e complementares ao conceito de sustentabilidade ecológica.

Aplicada à gestão empresarial, a sustentabilidade é comumente compreendida como "um modelo de gestão de negócios que visa ao retorno (lucro) para os acionistas, envolvendo o desenvolvimento econômico, a promoção social e a proteção dos recursos naturais do planeta” (Elkington, 1999, p. 397).

A economia neoclássica submete sociedade e ambiente, nessa ordem, ao sistema econômico. Tal paradigma crê na tecnologia para uso eficiente, ou até para substituição, dos recursos naturais no médio ou longo prazo. Como uma evolução deste modelo, surge a economia ambiental, representada pelo equilíbrio das dimensões social, ambiental e econômica. Conhecido pelo tripé da sustentabilidade (tripple bottom line) (Elkington, 1994), esse paradigma não desafia dogmas sobre os quais a ordem econômica global e a gestão empresarial se apoiam. Entre eles, destacam-se os dogmas do crescimento econômico ilimitado em um planeta de recursos finitos; da racionalidade do sistema e dos agentes econômicos; e da relação direta entre produtividade e aumento da riqueza e bem-estar social (Veiga, 2005; Bursztyn \& Bursztyn, 2012; Martinez-Alier, 2015).

Assim, a economia ambiental ainda deixa, na prática, sociedade e natureza à mercê do sistema econômico e dá voz à 
chamada "sustentabilidade fraca”, que se ancora na elucubração de que biodiversidade, bem-estar social, conhecimentos e saberes podem ser convertidos e medidos em termos de "capital", formando os capitais natural, social e humano (Victor, Susan, \& Kuburski, 1998).

A economia ecológica propõe a reorganização das três dimensões a partir do entendimento de que a economia é um subsistema da sociedade, que, por sua vez, é um subsistema do meio ambiente. Os preceitos apresentados por esse paradigma para o funcionamento e a regulação da economia e das organizações pautam-se na subserviência ao bem-estar social e no limite imposto pelo sistema natural (Romeiro, 2012). A sustentabilidade tida como "forte" transita para a economia ecológica ao assumir que a economia é um subsistema aberto do ecossistema global finito, este regido pelas leis da termodinâmica e com propriedades de irreversibilidade (Costanza, Daly, \& Bartholomey, 1991; Cechin, 2010), e ao reconhecer que os capitais não são plenamente intercambiáveis ou substituíveis (Jackson, 2013). Uma vez que os capitais manufaturado e humano estejam crescendo e o natural diminuindo, essa perspectiva identifica um problema para a panaceia do desenvolvimento sustentável, já que os dois primeiros dependem do último (Victor et al., 1998; Veiga, 2007).

A sustentabilidade "muito forte" implica, no limite, o estado estacionário e/ou decrescimento, considerando que o sistema natural tem pontos de inflexão que, quando ultrapassados, levam à perda de características biofísicas essenciais dos ecossistemas (Turner, Doktor, \& Adger, 1994; Latouche, 2009; GeorgescuRoegen, 2013), reforçando assim a noção de irreversibilidade e de limites para o sistema econômico, com base na capacidade de suporte do planeta (Bismarchi, 2011). Conceber pontos de inflexão significa reconhecer uma dinâmica complexa para além do trade-off entre os tipos de capital e a entrada em cena do pensamento sistêmico que, a partir dessa perspectiva, deveria ganhar espaço na gestão empresarial.

Os diferentes paradigmas repercutem na atribuição de objetivos e abrangências distintos à sustentabilidade (Hediger, 1999), em apreensões divergentes sobre o propósito e o papel das organizações e éticas empresariais dissonantes regendo sua atuação e relações com múltiplos stakeholders (Sólon, 2019).

\section{Resgate de propósitos e fortalecimento de resiliência}

Muito se tem debatido sobre o futuro iminente nos sentidos de retomada (Miguel \& Paiva, 2020), reconstrução (Monzoni \&
Carvalho, 2020; Gallagher, 2020), “novo normal” (Insper, 2020), ou simplesmente pós-pandemia (Morin, 2020). No espectro entre uma nova estabilidade com a manutenção do status quo e as transformações de ordem sistêmica, é certo que as empresas têm papel determinante no desenho desse futuro emergente.

Em 2014 os editores do Academy of Management Journal (AMJ) convocavam acadêmicos a investigar os objetivos pelos quais empresas são criadas e, depois, as trajetórias pelas quais eles se perdem, alertando que se fazia urgente reformular a compreensão coletiva sobre o propósito dos negócios no bojo de uma revisão do que queremos como cidadãos, atores políticos e consumidores (Hollensbe, Wookey, Hickey, George, \& Nichols, 2014). Empresas são organizações sociais, autorizadas pela sociedade a operar com o propósito primordial de responder às necessidades da própria sociedade (Belinky, 2017).

O clamor dos editores do AMJ ganha contornos trágicos à medida em que o colapso sanitário da Covid-19 explicita o embate entre o sistema econômico, regido pela crença no crescimento ilimitado, e a vida humana, que depende da natureza e carece de organizações sociais de suporte. Na atual situação, tal embate desdobra-se em decisões cotidianas entre "vida, morte e economia" (The Economist, 2020), não apenas por parte dos líderes e gestores públicos, como também de executivos do setor privado, chegando aos cidadãos como um paradoxo de sobrevivência a ser resolvido.

Nos últimos anos, o imperativo da resiliência disseminou-se nas agendas pública e privada, povoando discursos de líderes empresariais e organizações internacionais como Fórum Econômico Mundial (Howell, 2020) e Banco Mundial (World Bank, 2013) e ganhando força frente à escalada de incertezas. Resiliência, porém, pode tanto estar ancorada na engenharia - com o sentido de capacidade de retorno ao estado original ou de manutenção da estabilidade frente ao estresse quanto em uma perspectiva ecológica - em que resiliente é o sistema que recupera o equilíbrio após uma perturbação - ou sistêmica - relacionada à capacidade do sistema de manter seu desenvolvimento, encontrando novos equilíbrios (Davoudi et al., 2013; Abdulkareem \& Elkadi, 2018). Esta última ganha sentido evolucionário ao se entender que sistemas podem transformar a si próprios a partir de estresses e ameaças, ou mesmo em um processo contínuo de transformação, mantendo suas funções essenciais e capacidade de perpetuação por meio de ciclos adaptativos (Davoudi et al., 2013; Loorbach \& Wijsman, 2013).

A discussão sobre resiliência, seu significado, implicações e relação com a agenda de sustentabilidade avança desde a década de 1970, antes mesmo da disseminação do conceito de desenvolvimento sustentável com o Relatório Brundtland de 
1988. Lélé (1998) traz uma reflexão crítica acerca do conceito de resiliência a partir de publicações desde os anos 1970 até o fim dos anos 1990 e apresenta resiliência (com base em Holling, 1973) como o tamanho do domínio de estabilidade em torno de um ponto de equilíbrio frente às oscilações constantes, em substituição à busca por estabilidade. Ao ressaltar a importância da não-linearidade, intrínseca às noções de complexidade (Morin, 2008) e transição (Loorbach, 2007; 2010), e argumentar que situações de estresse causadas pela própria ação humana requerem mudanças de comportamento (e de bases regulatórias), o autor propõe o conceito de adaptabilidade, em que o domínio de equilíbrio é rompido e o sistema deve se reorganizar para seguir desempenhando suas funções essenciais e cumprindo seu propósito.

Retomada por Sucháček (2013) e Matarrita-Cascante et al. (2016), a discussão sobre adaptabilidade e resiliência é importante para diferenciar a busca pelo retorno a um estado de equilíbrio dentro de um mesmo domínio, portanto sobre as mesmas bases e mantendo as características principais do sistema (seja em relação ao equilíbrio climático global, seja no que concerne à matriz econômica de uma região ou país, sua dinâmica competitiva ou negocial), da ideia de mudança de domínio, que implica a transformação das bases de operação do sistema, a partir da qual não é possível voltar ao ponto de equilíbrio anterior já que o contexto estrutural não é mais o mesmo. A atual crise sistêmica denota a complexidade em que operam as organizações e suas relações frente às incertezas de caráter ontológico e que, portanto, não podem ser 'holisticamente' gerenciadas ou reduzidas (Grau-Solés et al., 2011).

A noção de resiliência evolucionária, proposta mais tarde por Davoudi et al. (2012) e Davoudi, Brooks, \& Mehmood, (2013) incorpora a adaptabilidade como uma característica necessária aos sistemas para que sejam capazes de avançar em ciclos contínuos de inovação, transformação e reorganização diante de distúrbios frequentes e de magnitude estrutural. No entanto, ainda não resolve o sentido dessa transformação.

Mirando as empresas, a inversão de propósito atualmente em vigor -- em que gerar valor para os acionistas tornou-se fim e não meio para atender às necessidades sociais -- combinada à falta de consciência e de responsabilização em relação aos limites ambientais e à degradação dos “comuns" a partir da operação dos negócios (Ostrom, 1999), é preciso combinar o fortalecimento de resiliência, no sentido evolucionário, ao paradigma da economia ecológica, erigindo não apenas instrumentos para uma gestão voltada à resiliência, mas também uma nova ética para a operação e para as relações dessas organizações sociais chamadas empresas.

À luz da crise sistêmica em voga, sustentabilidade e resiliência devem ser pensadas sem perder de vista o contexto mais amplo de transição de paradigma, cabendo a reflexão sobre o potencial de cada abordagem em despertar e alimentar questionamentos sobre premissas e valores em que se ancoram a lógica gerencial moderna. Enquanto a sustentabilidade estabelece objetivos, desenha caminhos e indicadores, a abordagem da resiliência fortalece a capacidade adaptativa e a robustez dos sistemas para que possam suportar choques inevitáveis e imprevisíveis (Redman, 2014). A sustentabilidade aufere riscos e traça rotas de adaptação envolvendo mudanças incrementais para manter o bem-estar, ganhos econômicos e sistema natural de suporte (Linkov et al., 2014). Por sua vez, a resiliência assume que decisões são tomadas com base em conhecimentos incompletos e experimentação, possibilitando transformações estruturais no sistema Kates, Travis, \& Wilbanksand, (2012).

Diante da confirmação de ameaças globais -- de doenças infecciosas a eventos climáticos extremos -- e das inegáveis incoerências no sistema socioeconômico, fazem-se necessárias transformações não-conjunturais, dentro de um mesmo domínio, mas estruturais nas engrenagens do sistema, tornando a abordagem da resiliência evolucionária mais promissora que a busca por sustentabilidade (Nelson, Adger, \& Brown, 2007). Assumindo a complexidade e a incerteza ontológica como dadas e irredutíveis, investir energia na análise do presente e na reflexão sobre os aprendizados até aqui se mostra mais produtivo do que conjecturar sobre o futuro pós-pandêmico. Mais do que prever o futuro, faz-se necessário refletir sobre o que faz alguns sistemas resilientes.

No mais, considerando que transições consistem não apenas na mudança nos componentes e na organização do sistema, mas também na formação de um sistema fundamentalmente diferente do anterior e operando em uma nova trajetória (Boyd \& Juhola, 2014), a abordagem de resiliência evolucionária mostra-se mais promissora que a busca por sustentabilidade ao desafiar a noção de estabilidade, conceber os sistemas como intrinsecamente complexos e permeáveis às mudanças de contexto e adaptáveis. Nesse sentido, tal abordagem carrega o potencial de provocar reflexões que vão além da análise de riscos e de modelos lineares baseados em causa e consequência. Ao propor sistemas interconectados, do nível organizacional ao socioambiental, em inevitável transformação contínua, a noção de resiliência evolucionária provoca o pensar a direção em que os sistemas se transformam, não isoladamente, mas como partes de um todo complexo. Portanto, é tempo de fortalecer resiliência de organizações que sejam capazes de resgatar suas contribuições para bem-estar geral, frente às demandas mais prementes da sociedade. Para tanto, é preciso repensar a gestão empresarial para sustentabilidade. 


\section{Gestão empresarial para resiliência}

Na visão da gestão empresarial, organizações resilientes atendem aos seguintes princípios (Reeves, Lang, \& Carlsson-Szlezak, (2020).; Folke, 2016; Wahl, 2019):

- Redundância: garantir capacidade adicional de produção, revertendo, em certa medida, o movimento de estoque zero e gestão por fluxos, agudizado na fase atual do capitalismo;

- Diversidade: múltiplas abordagens e perspectivas sobre um mesmo problema ou decisão podem ser menos eficientes, mas conferem flexibilidade e capacidade de resposta em crises, com soluções mais criativas, que não repliquem a lógica em operação (fundamental na proposta building back better);

- Modularidade: sistemas modulares -- em que fábricas, unidades organizacionais ou fontes de abastecimento se reorganizam e conectam de diferentes maneiras são mais resilientes;

- Capacidade adaptativa: capacidade de um sistema se transformar e evoluir frente a oportunidades, problemas ou sinais externos, valorizando o conhecimento, com processos de registro e disseminação de aprendizados, fluxos abrangentes de comunicação interna e externa e disponibilização de oportunidades e recursos necessários para a agência de áreas e colaboradores;

- Prudência: em situações de grande incerteza, embora devam se dedicar às transformações necessárias para um futuro melhor, é prudente que as empresas considerem os piores cenários em estratégias de contingência;

- $\quad$ Perceber-se parte: reconhecer-se parte de sistemas econômicos e sociais mais vastos, também sob pressão, e apoiar clientes, parceiros, fornecedores, governos, para fortalecimento dos sistemas de saúde e social, respalda relações de cooperação e confiança fundamentais para organizações resilientes.

Tais princípios demandam que a gestão empresarial crie oportunidades e condições para:
- Participação de diversos atores em espaços consultivos e deliberativos;

- Colaboração multistakeholder; e

- Aprendizagem organizacional.

A participação é um processo social ativo com engajamento mútuo dos atores em situação compartilhada e depende de instâncias formais e informais de interação e de condições, tangiveis e intangíveis, para que se possa efetivamente ocupar essas instâncias (Pelling \& High, 2005; Wenger, McDermott, \& Snyder, (2002). 0 processo de aprendizagem organizacional requer oportunidade de experimentação sem a pressão por resultados de curto prazo, além do registro dos aprendizados em base acessível, alimentando a memória organizacional e a construção de entendimentos comuns sobre conceitos e diretrizes (Salter \& Kothari, 2016).

\section{MÉTODO}

A busca por indícios sobre movimentos e adaptações das agendas de sustentabilidade em 13 empresas de grande porte s deu-se por meio de uma pesquisa qualitativa (Corbin \& Strauss, 2015; Reinecke, Arnold, \& Palazzo, (2016).) a fim de acessar elementos de um processo social complexo (Hamilton \& Finley, 2019), pautada na análise de narrativas aplicada como instrumento para compreender as inter- relações entre pessoas, acontecimentos e perspectivas a partir do contexto organizacional do narrador (entrevistado) (Maingueneau, 2015). Esse exercício combina a replicação da comunicação estratégica das organizações, seus valores e significados compartilhados (Boje, 2001) com a interpretação própria, com adição e destaque de elementos e trechos para criar a narrativa (Alves \& Blikstein, 2010), o que torna a organização e as motivações para contar a história tão substantivas para a pesquisa quanto o que está sendo narrado (Marvasti, 2019).

Considerando que as narrativas refletem valores, significados compartilhados, interesses e relações, enquanto constroem ou mantêm os sistemas sociais simbólicos (Bryman, 2012), a sua análise mostra-se apropriada no sentido de compreender como as práticas empresariais para sustentabilidade estão sendo pensadas e implementadas no contexto da crise sistêmica acentuada pela pandemia. Em construção, em especial nos primeiros meses do isolamento social no Brasil, as narrativas não são lineares, nem totalmente 
coerentes. Estão ainda emergindo, ganhando sentidos e sendo transformadas. As intenções dessa pesquisa limitam-se à identificação de indícios dos movimentos que se conformam nas agendas de sustentabilidade das organizações, sem a pretensão de confrontá-los com a realidade objetiva ou de prever seus desdobramentos.

\section{Contexto para a pesquisa}

A pesquisa foi conduzida no âmbito das Iniciativas Empresariais do Centro de Estudos em Sustentabilidade (FGVces) da Fundação Getulio Vargas, uma rede que reúne grandes empresas para o acesso e a produção de conhecimento e para a troca de experiências em torno da gestão empresarial para a sustentabilidade. A rede organiza suas atividades em ciclos anuais e o grupo de empresas participantes varia a cada ano. As 13 empresas envolvidas na pesquisa fazem parte da rede em 2020.

Ao longo do primeiro semestre do ano, os encontros presenciais foram substituídos por encontros virtuais quinzenais, organizados entre apresentação e discussão de conteúdos, com base em pesquisa e troca de experiências entre os participantes em relação às práticas empresariais e aos desafios enfrentados relacionados a questões socioambientais. Os temas em foco no ciclo 2020 foram atravessados pela pandemia da Covid-19, que se tornou a lente por meio da qual resiliência, governança e complexidade foram trabalhadas nos encontros entre os meses de março e maio.

\section{Coleta de dados}

Dois procedimentos foram combinados para a coleta de dados: a observação participante nos seis encontros online das Iniciativas Empresariais realizados entre março e maio de 2020; e entrevistas semiestruturadas com representantes de 13 empresas da rede. As entrevistas foram iniciadas com perguntas específicas e finalizadas com conversa aberta sobre entendimentos, experiências e perspectivas, permitindo que os entrevistados expressassem seus entendimentos subjetivos sobre práticas e desafios (Thomas, 2020). Dessa forma, o número restrito de entrevistas, apropriado para lançar luz a um nicho particular de pesquisa (Reinecke et al., 2016), resultou em um material rico a fim de compreender como a atuação em sustentabilidade era ou não repensada e reformulada em um momento de escalada da crise, e a resiliência passava ou não a insurgir como norte para a atuação empresarial.

Os entrevistados manifestaram seu interesse em participar a partir de convite aberto às 19 empresas participantes da rede. Os representantes entrevistados ocupam cargos que variam entre especialista, analista, gerente e diretor principalmente em áreas relacionadas a sustentabilidade, meio ambiente e responsabilidade social corporativa, conforme sistematizado no Quadro 1. As entrevistas foram realizadas por telefone, tiveram duração entre 40 e 60 minutos e foram registradas em planilha.

0 roteiro seguido para iniciar as entrevistas abarcou três perguntas:

- $\quad$ Quais as principais ações em curso nas agendas socioambientais prioritárias para a empresa?

- Que desafios se destacam para o avanço da atuação empresarial nessas agendas?

- $\quad$ O que segue e o que muda, em relação a estratégias e práticas, no contexto da pandemia da Covid-19?

As respostas a essas perguntas foram seguidas por uma conversa aberta sobre algumas das questões trazidas ou sobre a vivência, no nível pessoal e organizacional, dos ajustes impostos pelo isolamento social nas rotinas de trabalho e nas relações.

A observação participante em seis encontros virtuais, representados no Quadro 2, serviu para a melhor compreensão sobre alguns dos desafios enfrentados, ações em curso, mudanças ou acomodações na atuação das empresas nos temas socioambientais, propiciando a triangulação das informações levantadas (Roller, 2019). Os encontros foram organizados com exposição de conteúdo de pesquisa pela equipe do FGVces, seguida pela discussão pelo grupo e troca de experiências em salas menores. Cada encontro teve duração de duas horas e meia.

As discussões e experiências relatadas nos encontros foram registrados pela equipe do FGVces e contribuíram para a análise do conteúdo das entrevistas. Pelo menos duas pesquisadoras participaram das etapas de coleta de dados e um terceiro pesquisador envolveu-se na análise, garantindo uma “perspectiva de fora” (Gioia et al., 2013). 


\section{Quadro 1. Participantes das entrevistas semiestruturadas}

\begin{tabular}{c|l|l}
\hline & Setor principal de atuação & Posição institucional \\
\hline 1 & Financeiro & Assessor da Diretoria de Suprimentos, Infraestrutura e Patrimônio \\
\hline 2 & Financeiro & Analista de sustentabilidade \\
\hline 3 & Químico & Gestora corporativa de sustentabilidade \\
\hline 4 & Serviços & Especialista em sustentabilidade e diversidade \\
\hline 5 & Energia & Especialista em sustentabilidade \\
\hline 6 & Energia & Engenheira de meio ambiente \\
\hline 8 & Painéis de madeira, louças e metais & Coordenador de sustentabilidade \\
\hline 9 & Varejo & Analista sênior de sustentabilidade \\
\hline 10 & Varejo & Analista sênior de sustentabilidade \\
\hline 11 & Telecomunicações & Especialista em sustentabilidade \\
\hline 12 & Tecnologia & Especialista em responsabilidade social corporativa \\
\hline 13 & Gestão de ativos ambientais & Diretor de relações com governo e sustentabilidade \\
\hline
\end{tabular}

\section{Quadro 2. Encontros virtuais e temas tratados}

\begin{tabular}{l|c|c|c|c|c}
\hline Encontro & $\mathbf{1}$ & $\mathbf{2}$ & $\mathbf{3}$ & $\mathbf{4}$ & $\mathbf{5}$ \\
\hline Data (2020) & $19 / 03$ & $02 / 04$ & $23 / 04$ & $30 / 04$ & $14 / 05$ \\
\hline Temas em foco & $\begin{array}{c}\text { Sustentabilidade } \\
\text { no contexto do } \\
\text { Antropoceno }\end{array}$ & $\begin{array}{c}\text { Atuação } \\
\text { empresarial } \\
\text { diante da } \\
\text { pandemia }\end{array}$ & $\begin{array}{c}\text { Resiliência e } \\
\text { vulnerabilidade }\end{array}$ & $\begin{array}{c}\text { Governança } \\
\text { para sistemas } \\
\text { resilientes }\end{array}$ & $\begin{array}{c}\text { Casos } \\
\text { empresariais } \\
\text { transformadores } \\
\text { Casos das } \\
\text { Iniciativas } \\
\text { Empresariais }\end{array}$ \\
\hline
\end{tabular}

\section{Análise dos dados}

As informações levantadas nas entrevistas foram sistematizadas por empresa em torno das três perguntas da pesquisa, visões sobre a crise sistêmica revelada pela Covid-19, relações com outros atores e perspectivas para o pós-pandemia. Os elementos colhidos a partir da observação nos encontros foram somados em cada um desses agrupamentos iniciais, quando uma relação foi observada, seja ela de reforço, complementação ou dissonância, ou ainda aportando elementos do contexto organizacional, setorial ou social que apoiam ou justificam as ações narradas. A partir daí, foram criados códigos (Malterud, 2012) com base em unidades dos indícios sobre as estratégias e ações das 13 empresas no contexto da pandemia, atores envolvidos e desdobramentos nos médio e longo prazos.
Os códigos então tornaram-se os títulos de linhas e as empresas os de colunas, conformando uma matriz na qual foram reorganizados os indícios coletados. A partir dessa sistematização, novos códigos foram identificados e adotados, gerando uma segunda versão da matriz. A partir de uma visão transversal dos indícios trazidos pelos informantes das 13 empresas, os códigos foram agrupados nas categorias (Roller, 2019), ou linhas de ação em um processo interativo de reposicionamento de alguns indícios à medida que as categorias emergiram na análise considerando semelhança dos conteúdos. As seis categorias resultantes são representadas na Figura 1.

Importa ressaltar que a categorização não tem a intenção de classificar as empresas participantes como operando em uma forma específica de sustentabilidade, mas sim de compreender movimentos, adaptações e acomodações de algumas de suas ações. 


\section{DISCUSSÃO}

A Figura 1 sistematiza, em seis categorias, as linhas de ação. São elas: (1) ações inalteradas; (2) colaboração e comunicação; (3) organização do trabalho; (4) repercussão nos médio e longo prazos; (5) ações emergenciais e (6) áreas e agendas de sustentabilidade.

\section{Figura 1. Linhas de ação}

(1) Ações inalteradas
Foco em eficiência energética e melhoria
na gestão de emissões de GEE.
Meta de se tornar carbono neutra até
2030.
Treinamento de fornecedores sobre
normas da empresa.
Agenda ambiental "segue forte",
próximos movimentos: certificações e
inventário público de emissões de GEE.
Estudo e comunicação de pegada de
carbono de produtos.
Intenção da adoção blockchain para o
monitoramento da cadeia e do produto.
Foco em precificação interna de carbono.
Esforços para avançar na prática da
economia circular: implantar logistica
reversa.

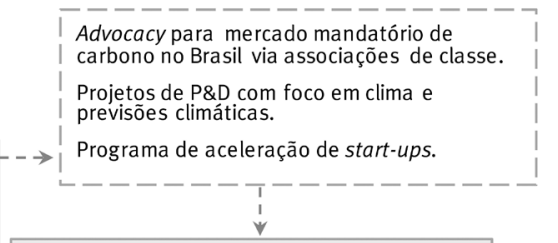

(2) Colaboração e comunicação

Comunicação com clientes, colaboradores e público em geral ganha força e a estratégia é pensada por áreas em conjunto.

Colaboração entre empresas do mesmo setor incluindo concorrentes, para "cuidar" de elos mais fracos da cadeia.

Oportunidade de colocar em prática modelos de colaboração.

\section{(3) Organização do trabalho}

Aceleração da digitalização de processos e de atendimento.

Home office com implicações nas relações, desafiando a colaboração causada pelo distanciamento.
(4) Repercussão no médio e longo prazos

Reflexão sobre remuneração de vendedores e sobre o papel da empresa na redução do consumo desenfreado.

Diagnóstico robusto sobre diversidade, abrang endo cultura interna e visão de clientes.

Esforço de conhecer os fornecedores para que não fechem na pandemia.

Cliente no centro da estratégia de projetos; produtos e serviços
assumem importância secundária.

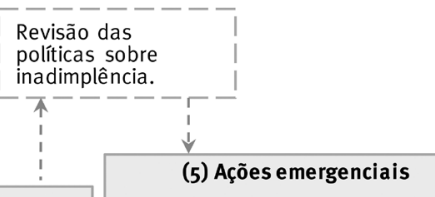

Garantir emprego e segurança de colaboradores.

Doações: distribuição de cestas básicas para comunidades; EPIs; merendas.

Redirecionamento total de recursos para ajuda humanitária.

Garantia de emprego dos colaboradores.

Suspensão de ações de desenvolvimento local que não sejam doações.

Plano estratégico de sustentabilidade alterado, investimentos direcionados para medidas emergenciais.
Pressão externa de demanda de acionistas por projetos de
transformação social.

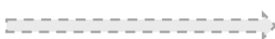

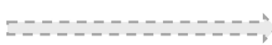

(6) Áreas e agendas de sustentabilidade

Desafio de fazer com que as estratégias se materializem na operação e nas demais áreas; a agenda fica em segundo plano frente às dificuldades operacionais do negócio.
Sustentabilidade incorporada às áreas de inovação (parcerias e apoios) e gestão de pessoas (projetos sociais)
Coordenação das operações das ações do COVID, promovendo outras áreas a se desenvolverem.
As seis categorias representadas sintetizam as informações coletadas nas entrevistas e por meio da observação dos participantes em que as narrativas sobre as ações empresariais em curso ou planejadas nos primeiros meses da pandemia da Covid-19 foram acessadas. A Figura 1 é resultado do processo de sistematização, codificação e análise dessas informações à luz do referencial teórico visitado.

As narrativas dessas organizações evidenciam, de um lado, agendas maduras, como a de mudança do clima, que congregam as forças de resistência e alimentam narrativas business as usual - de crença no mercado e flexibilidade frente a riscos - e de modelos e instrumentos financeiros como soluções (Wissman-Weber \& Levy, 2018), relacionadas aos preceitos da sustentabilidade fraca. De outro lado, movimentos que podem ser as sementes de mudanças estruturais, de médio e longo prazos, sintonizados em imaginários de comunidade, colaboração e na valorização do que é essencial, relacionados aos conceitos de sustentabilidade forte e resiliência.
Em “ações inalteradas”, o foco em eficiência energética, os esforços colocados em "treinamento de fornecedores nas regras da empresa" e a crença em certificações e precificação de carbono como rotas de salvação exemplificam a força de manutenção do sistema. Ao mesmo tempo, a intenção de avançar em "práticas de economia circular”, em detrimento da lógica linear, ainda que com foco único em logística reversa, traz um indício sutil de sustentabilidade forte e resiliência ao considerar limites ambientais e buscar matéria-prima no pós-consumo, o que pode reacomodar as relações de poder entre os elos da cadeia.

Movimentos e ações relacionados à comunicação e “colaboração" e "organização do trabalho" abarcam esforços para fortalecer a comunicação com diversos stakeholders, internos e externos; as interações entre colaboradores e parceiros, distanciadas pela virtualização; e até a colaboração entre empresas concorrentes, o que antes parecia impossível. Estas categorias apontam no sentido da sustentabilidade forte e da resiliência ao contribuírem para constituição de saberes e de espaços internos 
(e externos) de participação, colaboração, experimentação e aprendizagem, fundamentais para o aumento da capacidade adaptativa frente às questões socioambientais nem sempre passíveis de planejamento, tampouco de respostas únicas.

A categoria "repercussão nos médio e longo prazos", indica o interesse em reconhecer quem são os stakeholders para além dos contratos e relações mercantis, por meio de "diagnóstico robusto" sobre diversidade na organização e da escuta a fornecedores. Um movimento de aproximação com atores do sistema, sem um fim pré-determinado, representa um impulso por estreitamento de relações e consequente aumento de confiança e autonomia das partes, a fim de melhorar a capacidade de resposta em qualquer crise; pode também denotar premissas de controle, mais próximas à sustentabilidade fraca, ancorada em poder e dominação. Reposicionar "o cliente” no centro da estratégia do negócio e refletir sobre o papel da empresa em relação ao consumo desenfreado soam como indícios de transformações possíveis e potentes, seja pela revisão do propósito da empresa, seja pela disposição a repensar, questionar e mudar a cultura atual de consumo.

As "ações emergenciais" representam, em alguns casos, a suspensão de projetos e planos da sustentabilidade com o direcionamento total de recursos e equipes para assistência social e de saúde. Apontam, assim, a repriorização da vida em relação ao capital, mas deixam no ar o que virá na sequência, se a retomada de linhas de ação sintonizadas na sustentabilidade fraca, ou ações que contemplem os aprendizados da "emergência". A experiência de focar esforços em ações emergenciais relacionadas às necessidades humanas pode promover reflexões sobre os propósitos e valores da empresa, além de gerar aprendizados coletivos que podem, ou não, ser institucionalizados e favorecer a resiliência organizacional.

Por fim, despontam reflexões e mudanças sobre as "áreas e agendas de sustentabilidade". Em algumas empresas, a pandemia atravessou um processo, previamente em curso, de revisão da área e das estratégias; em outras, estimulou a transversalização da sustentabilidade, incorporada em áreas como de inovação e gestão de pessoas. Esses movimentos indicam uma crise em curso no que concerne à função da sustentabilidade diante do propósito da empresa, tanto pela compreensão de que as questões abrangidas devem estar presentes nas demais áreas de negócios, quanto pela repriorização de investimentos em projetos que geram retorno financeiro no curto prazo. 0 espectro também é grande entre o papel atribuído às áreas de sustentabilidade: da contribuição para a diferenciação da empresa, em um sinal de sustentabilidade fraca, à mobilização da organização para a ação coletiva coordenada.
Os achados nas seis categorias indicam pontos de fricção entre premissas e práticas que vigoraram nas agendas de sustentabilidade das empresas, consoantes do paradigma da economia clássica ou da economia ambiental, e uma visão ampliada sobre fazer negócios, que engloba elos das cadeias de valor, da matéria-prima ao pós-consumo, comunidades dos territórios em que as empresas estão presentes e parceiros de diferentes setores. Essa ampliação da sustentabilidade caminha no sentido da colaboração multistakeholder um dos pilares para resiliências no sentido evolucionário. Ainda, a revisão dos papéis e as atuações das áreas de sustentabilidade e correlatas no movimento de transversalização dos temas socioambientais provocam o repensar da governança refletindo a emergência de um novo momento da agenda, menos instrumental e mais próxima da gestão das atividades-chave dos negócios, o que indica um processo de aprendizagem organizacional em curso em parte das empresas e potencializados pelo contexto de crise.

Enquanto as ações emergenciais refletem a preocupação com necessidades prementes de grupos em situação de vulnerabilidade, configuram ações pontuais e de resposta mecânica às pressões sociais que convivem com a narrativa do fortalecimento da escuta das necessidades e visões também dos atores com os quais as empresas têm relações indiretas. Este último movimento provoca a reflexão sobre instâncias e canais de participação, o que também carrega o potencial de fortalecer a resiliência da empresa, assim como do sistema mais amplo em que ela se insere.

Tais fricções identificadas nas narrativas sobre as experiências e ações em curso nas empresas denotam um momento de bifurcação da agenda de sustentabilidade: de um lado a busca por qualquer resquício de segurança ancorada na sustentabilidade como fonte de informações para a gestão dos riscos que ameaçam o business as usual - na tônica da sustentabilidade fraca. De outro, a sustentabilidade como canal para que sociedade e meio ambiente permeiem os negócios, traduzidos em objetivos e limites para as atividades econômicas no sentido da sustentabilidade forte. A partir desse entendimento, pode-se tecer as seguintes considerações sobre o avanço no fortalecimento de resiliência no âmbito empresarial:

- Implica relações mais próximas e constantes com os atores externos, direta e indiretamente relacionados com os negócios da empresa;

- A resiliência não pode ser guiada somente pela aplicação de instrumentos padrão de gestão para sustentabilidade e demanda, além de instâncias 
perenes de participação e colaboração de atores internos e externos, a transversalização dos temas socioambientais nas áreas de negócio;

- $\quad$ Alinha-se à sustentabilidade forte no que concerne à internalização da noção de intrínseca relação entre a perenidade da organização e a capacidade de perceber e se transformar a partir do contexto ambiental e social. Porém fortalecer resiliência, mesmo no sentido evolucionário, não significa necessariamente assumir limites sociais e ambientais para as atividades econômicas; e

- Por carecer de instrumentos e experiência sistematizadas, embora fortemente presente no debate público, resiliência é um conceito mais abstrato do que prático dentro das empresas e mesmo no contexto da pandemia não foi adotada, nas empresas ouvidas, como norte para repensar ou complementar as ações de sustentabilidade ou mesmo o papel das áreas de sustentabilidade; a reflexão sobre o que faz das organizações sistemas resilientes não está instaurada nessas empresas.

Importante pontuar que as narrativas acessadas não revelaram indícios para todos os princípios de resiliência ou de sustentabilidade fraca ou forte; tampouco era esse o objetivo da pesquisa. Apontam, porém, que o aprendizado decorrente da pandemia pode ser um importante legado para lidar com desafios complexos que não desaparecerão com o controle desta doença.

Nesse panorama, as equipes de sustentabilidade e áreas correlatas são chamadas a alavancar transformações internas; por exemplo, provocando a leitura mais profunda sobre a conjuntura crítica do momento, resguardando e alimentando as instâncias e os fóruns de participação existentes, trabalhando pela diversidade de participação efetiva nos comitês de crise e, principalmente, para que os próprios projetos e ações de sustentabilidade possam emergir de interações significativas em fóruns multistakeholder, ou ao menos da escuta ativa das diversas partes envolvidas e interessadas. Ao se colocarem como agentes de mudança, os profissionais de sustentabilidade podem se lançar a provocar executivos, colegas, parceiros a enxergar além das imposições de curto prazo, e a inaugurar um processo amplo de reformulação do propósito da organização. Não com base em conjecturas de futuros incertos, mas na premência presente, histórica, de: conexão direta da organização com as pessoas afetadas pelo negócio, pela tradução nas estratégias e pelos critérios de decisão dos limites para a produção impostos pelo contorno ambiental; nos mecanismos de distribuição mais justa dos resultados econômico-financeiros da interação entre trabalho, tecnologia e recursos naturais; e no exercício da perspectiva resiliência evolucionária para pensar a capacidade de resposta da organização às pressões e oportunidades do contexto para transformar-se enquanto perpetua seu propósito primordial.

\section{CONCLUSÃO}

A pesquisa aqui apresentada revela que a agenda e as áreas de sustentabilidade são convocadas a assumir um escopo maior de atuação, dentro e fora das empresas, no contexto de instabilidade e incertezas acentuadas pela pandemia da Covid-19. A partir da revisão da literatura e da coleta e análise de informações sobre como 13 empresas estão lidando com a crise em seu momento inicial, a pesquisa contribui para a reflexão crítica sobre o papel da sustentabilidade para a construção de uma gestão e atuação empresarial pautadas no paradigma da economia ecológica, capazes de fortalecer a resiliência das organizações e dos sistemas dos quais fazem parte. Revela-se que forças de transformação e manutenção coexistem, disputam narrativas e espaço nas organizações, e que é crucial que estas se voltem aos seus propósitos primordiais, pelos quais existem.

Entre os indícios dos movimentos em curso nas empresas ouvidas, identifica-se o potencial de realinhamento ao propósito fundamental de atender às necessidades da sociedade e promover bem-estar de forma ampla, mas também se mostra latente o risco de seguir apostando no mercado - pela fé na tecnologia, inovação ou nos instrumentos financeiros - como fonte de soluções. Os esforços de comunicação e colaboração e de reconfigurar relações são promissores tanto pela ótica da sustentabilidade forte, quanto da resiliência. Embora as duas perspectivas não se alinhem completamente, há sinergias entre a transição para a sustentabilidade forte e o fortalecimento de resiliência e as duas contam o que pode vir a ser uma nova fase, emergente, da agenda empresarial de sustentabilidade. As categorias de ações e movimentos em curso identificados representam eixos pelos quais a transição pode se dar, ao mesmo tempo em que deixam claro que, em todos eles, há elementos de resistência e, portanto, de forças de manutenção ou retorno.

Ainda que os indícios identificados nesta pesquisa sejam de momentos iniciais da pandemia da Covid-19 e que outras ações e acomodações aconteçam, a experiência organizacional desse período, independentemente de qual tenha sido ela, compõe 
um saber fundamental para as empresas lidarem com outras manifestações da crise estrutural instaurada, e, em especial, com a própria crise por meio da transformação das organizações e dos sistemas em que atuam em prol da transição a um novo domínio. Nesse sentido, incorporar adaptabilidade na gestão e elevar as capacidades das empresas de perceber as perturbações, em toda sua complexidade, e transformarem a si e suas relações por meio de processos de aprendizagem organizacional despontam como medidas para que possam alcançar seu objetivo primordial de forma perene.

Como questões relevantes, surgem como possíveis focos para novas pesquisas o estudo sobre como a sustentabilidade forte e resiliência podem qualificar-se mutuamente, ao se complementarem e tratarem de questões semelhantes com intenções e vieses diferentes; a influência do setor econômico nas ações empreendidas pelas empresas diante da crise, assim como das matrizes dessas corporações, já que diretrizes globais por vezes determinam as agendas socioambientais no Brasil. Além disso, o mapeamento e a sistematização de casos empresariais relacionados ao fortalecimento de resiliência, em especial no sentido evolucionário, faz-se importante para que o conceito possa se traduzir na gestão empresarial. Como limitações da pesquisa, colocam-se a quantidade restrita de empresas cobertas pelas entrevistas e de profissionais ouvidos em cada empresa, o que resulta em uma fotografia que se presta à coleta de indícios e não a generalizações. Além disso, as entrevistas foram realizadas em um período inicial das medidas de isolamento social, cabendo investigar como os movimentos e as ações avançaram nos meses seguintes, e depois de findas as medidas.

Da ressignificação das relações entre empresas, cidadãos e governos, envolvendo novas dinâmicas de trabalho e de convivência pautadas por cooperação e compaixão, pode emergir uma outra ética. Para que esse seja o futuro próximo é preciso alimentar imaginários não de retomada ou reconstrução, mas de transformação. Para a gestão empresarial, significa um redirecionamento para aprendizagem, por meio do investimento, no presente, em diversidade, participação e diálogos efetivos. Processo esse para o qual a sustentabilidade empresarial é fundamental, ao mesmo tempo em que nunca esteve tão ultrapassada.

\section{REFERÊNCIAS}

Alves, M. A., \& Blikstein, I. (2010). Análise de Narrativas. In C. K. Godoi; R. Bandeira de Melo; A. B. Silva. (eds.), Pesquisa Qualitativa em Estudos Organizacionais: Paradigmas, estratégias e métodos (pp. 403-428). São Paulo: Saraiva.
Abdulkareem, M., \& Elkadi, H. (2018). From engineering to evolutionary, an overarching approach in identifying the resilience of urban design to ood. International Jornal of Disaster Risk Reduct, 28, 176-19o. doi:10.1016/j.ijdrr.2018.02.009

Belinky, A. (2017). Da empresa cowboy à astronauta. GVExecutivo, 16(5)18-21. doi: doi:10.1266o/gvexec.v16n5.2017.72915

Bismarchi, L. F. (2011). Sustentabilidade e inovação no setor brasileiro da construção civil: Um estudo exploratório sobre a implantação da política pública baseada em desempenho. (Dissertação de mestrado. Universidade de São Paulo). Recuperado de https://www.teses.usp. br/teses/disponiveis/90/90131/tde-05082011-215056/pt-br.php

Boje, D. M. (2001). Narrative Methods for Organizational \& Communication Research. Londres: Sage Publications.

Boyd, E., \& Juhola, S. (2015). Adaptive climate change governance for urban resilience. Urban Studies. 52(7), 1234-1264. doi: $10.1177 / 0042098014527483$.

Bresser-Pereira, L. C. (2018). Capitalismo financeiro-rentista. Estudos Avançados, 32(92), 17-29. doi:10.5935/0103-4014-20180003.

Bryman, A., (2012). Social Research Methods (4th Edition). Oxford: Oxford University Press.

Bursztyn, M., \& Bursztyn, M. (2012). Fundamentos de política e gestão ambiental: Os caminhos do desenvolvimento sustentável. Rio de Janeiro: Garamond.

Cechin, A. (2010). A natureza como limite da economia. São Paulo: SENAC/Edusp.

Corbin, J., \& Strauss, A. (2015). Basics of qualitative research: Techniques and procedures for developing grounded theory. Thousand Oaks, CA: Sage.

Costanza, R., Daly, H., \& Bartholomey, J. (1991). Goals, Agenda, and Policy Recommendations for Ecological Economics'. In R. Costanza, Ecological Economics: The Science and Management of Sustainability (pp. 1-20). New York, NY: Columbia University Press.

Davoudi, S., Shaw, K., Haider, L., Quinlan, A., Peterson, G., Wilkinson, C.,...Porter, L. (2012). Resilience: A Bridging Concept or a Dead End? "Reframing" Resilience: Challenges for Planning Theory and Practice Interacting Traps: Resilience Assessment of a Pasture Management System in Northern Afghanistan Urban Resilience: What Does it Mean in Planning Practice? Resilience as a Useful Concept for Climate Change Adaptation? The Politics of Resilience for Planning: A Cautionary Note. Planning Theory \& Practice, 13, pp. 299-333. doi: 10.1080/14649357.2012.677124

Davoudi, S., Brooks, E., \& Mehmood, A. (2013). Evolutionary Resilience and Strategies for Climate Adaptation. Planning Practice \& Research, 28(3),.307-322. doi: 10.1080/02697459.2013.787695

Elkington, J. (1994). Triple bottom line revolution: reporting for the third millennium. Australian CPA, 69.

Elkington, J. (1999). Cannibals with forks. Canada: New Society.

Folke, C. 2016. Resilience (Republished). Ecology and Society 21(4), 44. doi: 10.5751/ES-09088-210444

Gallagher, B. (2020). Rebuilding after COVID-19 shouldn't mean going back to how things were. Recuperado de https://www.weforum.org/ agenda/2020/06/covid-19-rebuilding-recovery/

Georgescu-Roegen, N. (2013). O decrescimento: Entropia, ecologia e economia. São Paulo: SENAC. 
Gioia, D.A., Corley, K.G., Hamilton, A.L. (2012). Seeking qualitative rigor in inductive research: notes on the Gioia Methodology. Organizational Research Methods. 16(1),15-31. doi: 10.1177/1094428112452151

Grau-Solés, M., Îniguez-Rueda, L., \& Subirats, J. (2011). ¿Cómo gobernar la complejidad? Invitación a una gobernanza urbana híbrida y relacional. Athenea Digital. Revista de Pensamiento e Investigación Social, 11(1), 63-84. doi: 10.5565/rev/athenead/v11n1.827

Harvey, D. (2020). Política anticapitalista em tempos de coronavírus. Recuperado de http://agbcampinas.com.br/site/2020/david-harvey-politica-anticapitalista-em-tempos-de-coronavirus/.

Hamilton, A. B., \& Finley, E. P. (2019). Qualitative methods in implementation research: An introduction. Psychiatry research, 280, 112516. doi: 10.1016/j.psychres.2019.112516

Hediger, W. (1999). Reconciling "weak" and "strong" sustainability. International Journal of Social Economics, 26(7/8/9), pp. 1120 1144. Recuperado de https://www.emerald.com/insight/content/ doi/10.1108/03068299910245859/full/html

Hollensbe, E., Wookey, C., Hickey, L., George, G., \& Nichols, C. V. (2014). Organizations with purpose. Academy of Management Journal, 57(5), 1227-1234. doi: 10.5465/amj.2014.4005

Howell, L. (2020). How to boost global resilience to COVID-19. World Economic Forum Global Agenda. Recuperado de https://www. weforum.org/agenda/2020/04/how-to-boost-global-resilience-tocovid-19/

Insper (2020). Novo Normal: Entenda Melhor esse Conceito e Seu Impacto em Nossas Vidas. Recuperado de https://www.insper.edu. $\mathrm{br} /$ noticias/novo-normal-conceito/

Jackson, T. (2013). Prosperidade sem crescimento. São Paulo: Planeta Sustentável.

Kates, R. W., Travis, W. R., \& Wilbanksand, T. J. (2012). Transformational adaptation when incremental adaptations to climate change are insufficient. Proceedings of the National Academy of Sciences of the United States of America, 109(19), 7156-7161. doi: 10.1073/ pnas.1115521109

Latouche, S. (2009). Pequeno tratado do decrescimento sereno. São Paulo: WMF Martins Fontes.

Lélé, S. (1991). Sustainable development: A critical review. World Development, 19(6),607-621.doi:doi:10.1016/0305-750X(91)90197-P

Lélé, S. (1998). Resilience, sustainability, and environmentalism. Environment and Development Economics, 3(2), $249-254$. Recuperado de http://www.jstor.org/stable/44379220

Linkov, I., Bridges, T., \& Creutzig, F. , Decker, J., Fox-Lent, C., Kröger, W., ... Thiel-Clemen, T. (2014). Changing the resilience paradigm. Nature Climate Change 4, 407-409. doi: 10.1038/nclimate2227

Liu, X., Rohr, J. R., \& Li, Y. (2013). Climate, vegetation, introduced hosts and trade shape a global wildlife pandemic. The Royal Society. doi: $10.1098 /$ rspb.2012.2506

Loorbach, D. (2007). Transition Management: New Mode of Governance for Sustainable Development. Utrecht: International Books.

Loorbach, D. (2010). Transition Management for Sustainable Development: A Prescriptive, Complexity-Based Governance Framework. Governance: An International Journal of Policy, Administration, and Institutions, 23(1), 161-183. doi: 10.1111/j.14680491.2009.01471.x

Loorbach, D., \& Wijsman, K. (2013). Business transition management: Exploring a new role for business in sustainability transitions. Journal of Cleaner Production, 45, 20-28. doi: 10.1016/j.jclepro.2012.11.002
Maingueneau, D. (2015). Discurso e Análise do Discurso. São Paulo: Parábola.

Martinez-Alier, J. (2015). Economia Ecológica. In J. Wright (Ed.), International Encyclopedia of the Social and Behavioral Sciences, 22. Elsevier

Marvasti, A.B. (2019). Qualitative Content Analysis: A Novice's Perspective. Forum: Qualitative Social Research, 20(3). doi: 10.17169/ fqs-20.3.3387

Matarrita-Cascante, D., Trejos, B., Qin, H., Joo, D., \& Debner, S. (2016). Conceptualizing community resilience: Revisiting conceptual distinctions. Community Development, 48, 105-123. doi: https://doi. org/10.1080/15575330.2016.1248458

Miguel, P. L. de S., \& Paiva, E. L. (2020). O rearranjo das cadeias globais de suprimentos. GVExecutivo, 19(3). Recuperado de https://rae. fgv.br/gv-executivo/vol19-num3-2020/rearranjo-cadeias-globaissuprimentos

Monzoni, M., \& Carvalho, A. (2020). Pós-Covid-19: Reconstruir para melhor. GVExecutivo, 19(3). Recuperado de https://rae.fgv.br/gv executivo/vol19-num3-2020/pos-covid-19-reconstruir-para-melhor

Morin, E. (2008). Introdução ao Pensamento Complexo. Lisboa: Instituto Piaget.

Morin, E. (2020). Um festival de incerteza. Recuperado de http://www. ihu.unisinos.br/78-noticias/599773-um-festival-de-incerteza-artigode-edgar-morin

Nelson, D. R., Adger, W. N., \& Brown, K. (2007). Adaptation to environmental change: Contributions of a resilience framework. Annual Review of Environment and Resources, 32, 395-419. doi: https://doi.org/10.1146/annurev.energy.32.051807.090348

Ostrom, E. (1999). Coping with tragedies of the commons. Annual Review of Political Science, 2, 493-535. doi: https://doi.org/10.1146/ annurev.polisci.2.1.493

Pelling, M., \& High, C. (2005). Social learning and adaptation to climate change. Benfield Hazard Research Centre. Disaster Studies Working Paper, 11, 1-19. Recuperado de https://www.researchgate. net/publication/228375537_Social_learning_and_adaptation_to_ climate_change

Redman, C. L. (2014). Should sustainability and resilience be combined or remain distinct pursuits? Ecology and Society, 19(2), 37. doi: http://dx.doi.org/10.5751/ES-06390-190237

Reeves, M., Lang, N., \& Carlsson-Szlezak, P. (2020). Lead Your Business Through the Coronavirus Crisis. Recuperado de https://hbr. org/2020/02/lead-your-business-through-the-coronavirus-crisis

Reinecke, J., Arnold, D. G, \& Palazzo, G. (2016). Qualitative methods in business ethics, corporate responsibility, and sustainability research. Business Ethics Quarterly, 26 (4), 12-22. doi: https://doi. org/10.1017/beq.2016.67

Roller, M. (2019). A quality approach to qualitative content analysis: Similarities and differences compared to other qualitative methods. Forum: Qualitative Social Research, 20(3). doi: http://dx.doi. org/10.17169/fqs-19.3.3385

Romeiro, A. (2012). Desenvolvimento sustentável: Uma perspectiva econômico-ecológica. Estudos Avançados, 26(74). doi: http://dx.doi. org/10.1590/S0103-40142012000100006. 
Salter, K. L., \& Kothari, A. (2016). Knowledge 'Translation' as social learning: Negotiating the uptake of research-based knowledge in practice. BMC Medical Education, 16(76), 1-10. doi: https://doi. org/10.1186/s12909-016-0585-5

Santos, B.S. (2020). Vírus:Tudooqueésólidosedesfaznoar. Recuperado de https://www.sul21.com.br/opiniaopublica/2020/03/virus-tudoo-que-e-solido-se-desfaz-no-ar-por-boaventura-de-sousa-santos/

Sólon, P. (2019). Alternativas Sistêmicas. São Paulo: Elefante.

Sucháček, J. (2013). On the emergence of resilience and adaptability: An evolutionary perspective. Journal of Economics and Management, 10, 21-30. Recuperado de https://www.ue.katowice.pl/fileadmin/_ migrated/content_uploads/2_Suchacek_On_The_Emergence_of_ Resilience_and_Adaptability....pdf

The Economist (2020). Covid-19 presents stark choices between life, death and the economy. The trade-offs required by the pandemic will get even harder. Recuperado de https://www.economist.com/ leaders/2020/04/02/covid-19-presents-stark-choices-between-lifedeath-and-the-economy.

Thomas, K. (2020). Cultures of Sustainability in the Fashion Industry, Fashion Theory, 24:5, 715-742. doi: https://doi.org/10.1080/136270 4X.2018.1532737

Turner, R. K., Doktor, P. and Adger, N. (1994). Sea-level rise and coastal wetlands in the UK: mitigation strategies for sustainable management. In: C. Folke, M. Hammer, R. Costanza and A. Jansson (Editors), Investing in Natural Capital. The Ecological Economics Approach to Sustainability, pp. 266-290. Washington: Island Pres
Veiga, J. (2005). Desenvolvimento Sustentável: O desafio do século XXI. Rio. Rio de Janeiro: Garamond.

Veiga, J. (2007). A emergência socioambiental. São Paulo: SENAC.

Victor, P., Susan, H., \& Kuburski, A. (1998). How Strong is Weak Sustainability? O. M. Faucheux S., Sustainable Development: Concepts, Rationalities and Strategies. Economy \& Environment (Vol. 13). Springer: Dordrecht.

Wahl, D. (2019). Nurturing Vital Diversity \& Resilience: Scaling Out, Rather than Scaling-Up! Recuperado de https://www.resilience.org/ stories/2019-11-15/nurturing-vital-diversity-resilience-scaling-outrather-than-scaling-up/.

Wenger, E., McDermott, R. A., \& Snyder, W. (2002). Cultivating communities of practice: $A$ guide to managing knowledge. Massachusetts: Harvard Business Press.

Wissman-Weber, N., \& Levy, D. (2018). Climate adaptation in the Anthropocene: Constructing and contesting urban risk regimes. Organization (25) 4, 491-516 doi: https://doi. org/10.1177/1350508418775812.

World Bank (2013). Building Resilience: Integrating Climate and Disaster Risk into Development. Washington, DC. Recuperado de https:// openknowledge.worldbank.org/handle/10986/16639.

World Economic Forum (2020). The Global Risks Report 2020. Insight Report (15th Edition). In partnership with Marsh \& McLennan and Zurich Insurance Group. Recuperado de http://www3.weforum.org/ docs/WEF_Global_Risk_Report_2020.pdf.

Zalasiewicz, J. (2015). Disputed start dates for Anthropocene. Nature, 520, 436. doi: https://doi.org/10.1038/520436b

\section{CONTRIBUIÇÃO DOS AUTORES}

Mariana Nicolletti, Gabriela Alem e Paola Fillippi trabalharam na conceitualização e abordagem teórica-metodológica. A revisão teórica foi conduzida por Luis Felipe Bismarchi. A coleta de dados foi coordenada por Mariana Nicolletti e participaram da coleta e sistematização Gabriela Alem e Marta Blazek. A análise dos dados foi realizada por Mariana Nicolletti e Gabriela Alem. Todos os autores participaram da redação e revisão final do manuscrito. 